\title{
Concepts in monitoring the treatment in rheumatoid arthritis - the role of musculoskeletal ultrasound. Part I: synovitis.
}

\author{
Mihaela Cosmina Micu' ${ }^{1}$, Daniela Fodor ${ }^{2}$
}

${ }^{1}$ Rheumatology Division, Rehabilitation Clinical Hospital, ${ }^{2}{ }^{\text {nd }}$ Internal Medicine Department, "Iuliu Hatieganu" University of Medicine and Pharmacy, Cluj-Napoca, Romania

\begin{abstract}
Rheumatoid arthritis (RA) is an incurable chronic inflammatory disease associated with significant functional impairment and disability, linked to inflammatory and structural articular and peri-articular damage. Structural damage occurs rapidly in RA if inflammation is not efficiently suppressed. Identification of patients with high risk to develop RA followed by an early application of efficient medications and standard 'treat to target' recommendations allow a better management aiming remission. Over the last 15 years musculoskeletal ultrasound (MSUS) has proved to detect subclinical inflammatory lesions; thus, targeting therapy to imaging delivered information may provide superior outcomes and a more rapid response to therapy detection in comparison with clinical examination alone. This review provides an insight into the importance of MSUS in quantifying disease activity and monitoring of therapies in RA patients.

Keywords: rheumatoid arthritis, imaging, musculoskeletal ultrasound, remission, treatment monitoring
\end{abstract}

\section{Introduction}

Rheumatoid arthritis (RA) is an incurable chronic inflammatory disease associated with significant functional impairment and disability, linked to inflammatory and structural articular and peri-articular damage. The main objective in RA management is to stop or to prevent the progression of joint damage and subsequently to reduce the degree of disability. Articular and peri-articular inflammatory process suppression represents the first step in limiting structural damage. Therefore, the start of an early, tailored treatment with synthetic and/ or biological disease-modifying anti-rheumatic drugs (DMARDS), corticosteroids, coupled with a 'treat to target' (T2T)

Received 10.06.2015 Accepted 30.06.2015

Med Ultrason

2015, Vol. 17, No 3, 367-376

Corresponding author: Daniela Fodor, $\mathrm{MD}, \mathrm{PhD}$

$2^{\text {nd }}$ Internal Medicine Department

"Iuliu Hatieganu" University of Medicine and Pharmacy, Cluj-Napoca, Romania

2-4 Clinicilor str, 400006 Cluj-Napoca, Romania

Phone: 004 0264591942/442

Email: dfodor@umfcluj.ro strategy aiming remission, represents the ultimate goal $[1,2]$.

\section{Measuring disease activity in RA}

The measurement of the disease activity in RA in clinical practice shows a trend in achieving a more standardized approach and includes, in the last years, a variety of instruments relying basically on various types of joint counts, laboratory blood analysis (inflammatory parameters, etc.), global assessment scales, pain scales, fatigue, etc $[3,4]$. Currently, there are several validated instruments available which combine a variety of parameters into different composite scores, allowing a standardized way to quantify the level of disease activity, according to their threshold level. The most popular activity scores used in clinical practice are: disease activity score counting 28 joints (DAS 28), simplified disease activity index (SDAI), and clinical disease activity index (CDAI). These scores are based on the clinical joint assessment [5-7]. Despite being a routine assessment, the detection of joint synovitis by palpation is still a subjective method with moderate inter-performer agreement. Indeed, clini- 
cal assessment of tenosynovitis is a true challenge with lesser efficient detection when compared with joint assessment $[8,9]$.

\section{The concept of remission and low disease activity in RA}

The main therapeutic objective in RA patients is to achieve remission status [10-12]. True remission should define the absence of symptoms, of inflammation and radiologic progression along with a stabilized functional status. Low disease activity (LDA) is a state characterized by minimal progression of joint damage and physical function and is a good alternative for patients who cannot attain remission because of comorbidities or other patient's factors and drug related risks [11]. Notably, patients who achieve sustained remission status or LDA present better functional outcomes and a better quality of life in parallel with a reduction in radiologic progression [2].

Traditionally, remission was defined according to the modified ACR criteria [13]. In time, several composite scores were developed such as DAS, DAS 28 [5,14], SDAI and CDAI, the last two with more strict treshold values in comparison to DAS 28 [7]. Of further note, these remission criteria were developed to assess therapy responsivness and outcomes for clinical trials purposes and work more effectively at a 'group level'. However, at 'patient level', clinical remission criteria are unable to perform accurately due to several factors such as clinical assessment insensitivity, modified patients pain tolerance (possibly influenced by other comorbidities) or lack of inflammatory parameters elevation. There is general agreement that these criteria may define LDA rather than true remission [15].

Independently from the instrument used to define remission, a significant percentage $(25-50 \%)$ of RA patients treated with synthetic DMARDs may continue to present radiological progression [16-19]. Actually, persistent active synovitis (subclinical) is one of its explanations and main predictor [20-22]. Indeed, $50 \%$ of the RA patients achieving remission will present flares in the next 24 months [17]. In this context, clinical remission was recently redefined as a result of an ACR and EULAR collaboration initiative. The actual ACR/ EULAR 2011 remission criteria are still based on clinical evaluation of inflammatory joint modifications but has more restrictive requests. The Boolean and index based definitions are fulfilled when a patient's scores on the following measures are all $\leq 1$ : tender joint count (TJC), swollen joint count (SJC), C reactive protein, and patient global assessment or when a patient's score on the SDAI is $\leq 3.3$
[23]. In the last years, significant effort has been made for better identification of early RA patients, in order to tailor an earlier treatment and to implement a monitoring schedule in accordance with T2T strategies. This approach may contribute to making remission a feasible target [11,24-29].

\section{Musculoskeletal ultrasound use in RA}

The easier access and acceptable healthcare costs for new, high resolution, imaging methods such as musculoskeletal ultrasound (MSUS) and MRI facilitates a more accurate depiction of inflammatory and structural multi- tissue lesions, in comparison to clinical examination (CE) [30-40]. In fact, in RA, there is a very good correlation between imaging delivered information and laboratory inflammation parameters, allowing a better disease activity assessment when using these tools [41].

In the last 15 years MSUS has gained an increasingly important role in the evaluation and treatment monitoring of RA. B-mode or grey scale (GS) scanning allows direct visualizing of the morphology and quantity (hypertrophy) of the synovial tissue. Doppler techniques such as power Doppler (PD), color Doppler (CD), and spectral Doppler identify in real time the increased synovial micro-vascular blood flow. These parameters correlate with the level of disease activity at one given point in time [42-47]. Apart from GS and Doppler assessment of different structures, MSUS shows several other advantages such as high accessibility (it is routinely used in many rheumatology departments in and out-patient clinics), low cost in comparison to MRI, CT, and safety- i.e. lack of ionizing radiations [48]. The possibility to perform repetitive joint scanning, without any exposure to radiation, is ideal to maintain a tight control during the monitoring process $[49,50]$.

Longitudinal studies demonstrate that MSUS is able to detect response to therapy more rapidly in comparison to clinical examination or different clinical scores [36,51-53] and that MSUS monitored patients become more compliant to therapy and follow up schedule [54].

\section{Imaging acquisition}

MSUS assessmentassumes joint and peri-articular structures evaluation in GS and Doppler modalities, using the standard EULAR protocol [55]. Doppler methods are essential for identifying inflammatory lesions at baseline (previous to treatment commencement/ change of therapeutic strategy) and during follow up. In clinical remission status, the Doppler activity may show the presence of subclinical joint modifications. 
Any peripheral joint can be assessed by ultrasound. Doppler techniques are more sensitive for superficial structures and on the dorsal area in comparison to the volar/ plantar area. PD technique is preferred in clinical practice. It displays the total integrated Doppler power in color showing an increased sensitivity for low velocity flow detection, being independent of angulation and aliasing artifacts. PD evaluation is carried out by selecting the target (interest) region that has to include the cortical bone, joint space and a variable quantity of adjacent tissue. The color box should include all superficial layers (also the skin) thus avoiding misinterpretation of movement artifacts. Several parameters have to be set in order to increase the sensitivity of Doppler signal detection. The pulse repetition frequency (PRF) should be low, around $500-800 \mathrm{~Hz}$, the Doppler frequency should be the highest possible for superficial structures and lower for profound tissues, the gain will be adjusted below the threshold to noise artifacts and the wall filter should be low. These parameter settings should be adjusted in accordance with the target region and from patient to patient, if needed. For longitudinal, correct, assessments and multicenter studies it is advisable to keep the same set-up and the same ultrasound machine [56]. Qualitative, semi-quantitative and quantitative scoring systems have been used for assessing synovitis by GS and/or PD in a different number of joints [57]. In practice the most frequently used is the 4 grade semi-quantitative scoring system for GS and PD developed by Szkudlarek et al (Table I) $[58]$.

\section{The discriminative capacity and validity of MSUS in RA}

The successful application of the MSUS assessment in RA patients in clinical practice and trials relies in its ability to correctly identify, quantify and monitor changes in time. Its discriminative capacity (one of the three main pillars of the OMERACT filter), helpful in differentiating between normal and pathological findings, in assessing the efficacy of different medications and in evaluating the active or inactive disease status, is supported by the concepts of reliability (reproducible result) and responsiveness (sensitivity to external change, independent from changes generated by machine differences, image acquisition and interpretation experience) [41,58-60] .

The validity of MSUS in identifying inflammatory lesions is underpinned by correlations between the PD signal intensity and histopathology or contrast MRI of the same tissue [44,45,58,61-66]. Both, synovial histopathology and MRI are considered 'gold standard' methods for joint/ peri-articular tissue examination.

Sensitivity to change of MSUS defines the utility in monitoring RA treated patients and was demonstrated by now by a series of important studies on different therapies $[36,43,51,52,67-71]$.

\section{Clinical remission versus imaging remission}

There is a continuous concern regarding the performance of the actual remission criteria. The question is whether they really do reflect the remission status. Several studies report a significant discrepancy between clinical and imaging findings in RA patients achieving clinical remission. In these circumstances, the question to be answered is if clinical remission is followed also by imaging remission [18,20,27,72-84]. In fact, a variable percentage (25-50\%) of RA patients continue to present active synovitis (detected by MSUS and MRI) and high disease activity scores during clinical remission, independently from the type of the applied remission criteria (more lax or restricted). The persistence of subclinical inflammation semms to be correlated to angiogenic factors elevation and to radiologic progression in patients with clinical remission or LDA [18,20,77].

In line with these findings, a number of studies highlight that the number of PD positive joints at baseline represents a predictor factor for future disease relapses. Likewise, the degree of the PD signal at baseline is a predictor for radiologic progression in early RA $[22,36,65,79,85,86]$ as well as in longstanding RA $[52,69,87-90]$. In this respect, subclinical active synovitis could be considered a surrogate marker to define the disease activity or a complete remission status in treated RA patients [18,79,91-93].

When adequate therapy is early prescribed ('window of opportunity') a higher percentage of patients achieve remission. Likewise, a higher percentage have chances

Table I. The 4 grade semi-quantitative scoring system for grey-scale and power Doppler synovitis assessment (after [58], adapted).

\begin{tabular}{lll}
\hline Grade & GS synovitis & PD synovitis \\
\hline 0 & absence of synovial thickening & absence of signal, no intra-articular flow \\
1 & mild synovial thickening & mild, $1-2$ vessels signal for small joints and $2-3$ for large joints \\
2 & moderate synovial thickening & $<50 \%$ of normal synovial area \\
3 & marked synovial thickening & marked vessels' signals in $>50 \%$ of the synovial area \\
\hline
\end{tabular}


for sustained remission after biologic DMARDs tapering or arrest attempts in comparison to patients with delayed start of the therapy [76,94-98]. Early RA patients in remission (DAS $<1.6$ ) had lower PD scores and absence of imaging synovitis (GS and PD) in $43 \%$ in comparison to only $17.4 \%$ of those with long standing RA [74].

Patients who receive first line biologic therapy have GS synovitis in a significantly lower percentage in comparison with the groups treated with biologics acording to the present recommendations (failure to 2 synthetic DMARDs) but the number of PD positive joints remain comparable between the groups. This observation led to the conclusion that GS synovitis correlates with disease duration (duration of inflammation and subsequent fibrotic changes) and PD positive synovitis is an independent parameter and a better marker for inflammation at one point in time [18,77].

Remision at one point must be differentiated from sustained remission (>18 months), the last one being correlated to joint scores, radiologic progression, and residual disfunction reduction $[99,100]$. This information is important when readjustment of treatment strategy (tapering/ arrest) is discussed [77,101].

\section{Number of monitored joints, type of joints, and MSUS scoring systems}

In clinical practice, it is advisable to follow the EULAR guidelines for MSUS evaluation in GS and PD [55], to be familiarized with Doppler techniques $[56,102]$, and with actual scoring systems and composites instruments for disease activity assessment [103].

Developing scoring systems for synovitis is important for several reasons. Firstly, it facilitates homogenous therapeutical decisions in a certain moment of disease evolution (therapy commencement, tapering process, or arrest) and secondly, it allows longitudinal efficacy evaluation for specific therapies. In time, the first scores developed were independent MSUS scores (GS, PD), targeting single joints. Afterwards, global scoring systems quantifying inflammation at patient level were elaborated [57]. Furthermore, there were attempts to incorporate MSUS information in composite scores as DAS [71] or to develop multimodal scores consisting of a combination between clinical and MSUS information. In this respect, subclinical inflammatory lesions, low degree or borderline lesions difficult to be identified by clinical examination, may add new information and optimise medical decisions $[104,105]$.

Any quantification system used has to pass the OMERACT filter and confirm validity, discriminative capacity and to prove fesability. Fesabilty implies also the possibility to explore the smallest number of joints and tendons which will offer enoungh information for inflammation amount evaluation.

There is no consensus yet regarding the number of joints to be included in an efficient synovitis scoring system. Reduced joint number scoring systems like 12 joints [52], 7 joints [106], 6 joints [107] perform similarly to the extended ones in terms of clinical and laboratory variables $[70,105,108,109,110]$.

Future studies are necessary to clarify this aspect. Up to now, MSUS evaluation is considered to be superior (more accurate) to clinical examination but its sensitivity to change is not $[41,111]$, possibly due to the fact that clinical scores and composite clinical- MSUS scores measure the same pathological finding- synovitis. Recent studies showed already the importance of separate synovitis and tenosynovitis (accurately detected with MSUS) monitoring under biologic therapy $[67,112]$. In this regard, multimodal composite scores have not been tested yet $[104,113]$.

In practice, large joints are less important for disease monitoring in comparison to small joints. For remision assessment, main studies included wrist area and MCP of the dominant hand as a minimal set [110].

\section{The relevance of MSUS lesions for diagnosis and remission}

There is an ongoing debate regarding the relevance of MSUS lesions for diagnosis and remission $[92,103,114,115]$.

Defining total imaging inflammation abolition (absence of GS and PD signal) is an exigent target. In this regard, a more feasible desideratum seems to include only sufficient diminution or abolition of PD activity. The minimal accepted synovial activity threshold is still not clearly defined but the median scores in grey scale less then 1 and in PD less then 0.5 based on 5 joint scanning (MCP 2-5 and wrist of the dominant hand 4 grade semi-quantitative score) correlate with a negative radiologic evolution [18].

\section{Follow up frequency}

The follow up frequency for MSUS evaluation has to be further clarified. In the short term MSUS has proved to be a feasible tool in synovial perfusion change induced by different therapies (biologics, CS) $[36,43,53,67,116]$. Long term studies $(>1$ year) are few [113]. Statistical significance was obtained only at 3038 weeks due to the low patients number included in the studies [117,118]. 


\section{Ankle and feet synovitis in $\mathrm{RA}$ remission assessment}

Ankle and feet synovitis is present in about $36 \%$ of the RA patients [119]. There is clear underestimation of joint involvment when applying remission criteria such as DAS 28- ESR, SDAI, CDAI in comparison to ACR 1981 or ACR/EULAR 2010 criteria which count all joints [120]. Residual synovitis is present in $20 \%$ of these patients drawing in a subsequent high risk for radiological progression. Hence, actual recommendations (not firmly required) are to include ankle and feet in the routine joint evaluation [23,121].

\section{Grey scale - grade I synovitis}

Approximately $56 \%$ of all evaluated synovitis are grade I. Clinical examination cannot identify this modification which is not accompanied by swelling or pain. Currently, grade I synovitis is considered nonspecific for RA, being present in about $15 \%$ of the controls and without therapeutical relevance according to some authors opinion [114]. Indeed, a low PD grade associated to GS grade I may not necessarily reflect active synovitis [117]. On the contrary, according to a recent published study, GS grade I synovitis is not encountered in healthy subjects [122]. Future agenda has to define the acceptable or reasonable MSUS synovitis and the limit up to which treatment is unnecessary. This issue has to be clarified in regard to biologic tapering attempts or over- treatment risk [123].

\section{Conclusions}

MSUS, especially PDUS activity monitoring in target joints is a feasible and patient friendly method, complementary to clinical examination, helpful in guiding clinicians to chose the right treatment strategy and to strictly monitor it in patients with RA. Current EULAR recommendations on the use of imaging in RA, based on the best availlable research evidence and expert opinion, include MSUS as a valuable tool for clinical practice [124].

\section{Conflict of interest: none}

\section{References}

1. Smolen JS, Aletaha D. Rheumatoid arthritis therapy reappraisal: strategies, opportunities and challenges. Nat Rev Rheumatol 2015; 11: 276-289.

2. Kavanaugh A, Fleischmann RM, Emery P, et al. Clinical, functional and radiographic consequences of achieving stable low disease activity and remission with adalimumab plus methotrexate or methotrexate alone in early rheumatoid arthritis: 26-week results from the randomised, controlled OPTIMA study. Ann Rheum Dis 2013; 72: 64-71.

3. Felson DT, Anderson JJ, Boers M, et al. The American College of Rheumatology preliminary core set of disease activity measures for rheumatoid arthritis clinical trials. The Committee on Outcome Measures in Rheumatoid Arthritis Clinical Trials. Arthritis Rheum 1993; 36: 729-740.

4. Smolen JS. The work of the EULAR Standing Committee on International Clinical Stu- dies Including Therapeutic Trials (ESCISIT). Br J Rheumatol 1992; 31: 219-220.

5. Prevoo ML, van 't Hof MA, Kuper HH, van Leeuwen MA, van de Putte LB, van Riel PL. Modified disease activity scores that include twenty-eight-joint counts: development and validation in a prospective longitudinal study of patients with rheumatoid arthritis. Arthritis Rheum 1995; 38: 44-48.

6. Smolen JS, Breedveld FC, Schiff MH, et al. A simplified disease activity index for rheumatoid arthritis for use in clinical practice. Rheumatology (Oxford) 2003; 42: 244257.

7. Aletaha D, Nell VP, Stamm T, et al. Acute phase reactants add little to composite disease activity indices for rheumatoid arthritis: validation of a clinical activity score. Arthritis Res Ther 2005; 7: R796-R806.

8. Fransen J, Creemers MC, Van Riel PL. Remission in rheumatoid arthritis: agreement of the disease activity score (DAS28) with the ARA preliminary remission criteria. Rheumatology (Oxford) 2004; 43: 1252-1255.

9. Hmamouchi I, Bahiri R, Srifi N, Aktaou S, Abouqal R, Hajjaj-Hassouni N. A comparison of ultrasound and clinical examination in the detection of flexor tenosynovitis in early arthritis. BMC Musculoskelet Disord 2011; 12: 91.

10. Emery P, Salmon M. Early rheumatoid arthritis: time to aim for remission? Ann Rheum Dis 1995; 54: 944-947.

11. Smolen JS, Aletaha D, Bijlsma JW, et al. Treating rheumatoid arthritis to target: recommendations of an international task force. Ann Rheum Dis 2010; 69: 631-637.

12. Radner H, Smolen JS, Aletaha D. Remission in rheumatoid arthritis: benefit over low disease activity in patient-reported outcomes and costs. Arthritis Res Ther 2014; 16: R56.

13. Pinals RS, Masi AT, Larsen RA. Preliminary criteria for clinical remission in rheumatoid arthritis. Arthritis Rheum 1981; 24: 1308-1315.

14. Van der Heijde DM, van't Hof MA, van Riel PL, et al. Judging disease activity in clinical practice in rheumatoid arthritis: first step in the development of a disease activity score. Ann Rheum Dis 1990; 49: 916-920.

15. Wakefield RJ, D'Agostino MA, Naredo E, et al. After treatto-target: can a targeted ultrasound initiative improve RA outcomes? Ann Rheum Dis 2012; 71: 799-803.

16. Cohen G, Gossec L, Dougados M, et al. Radiological damage in patients with rheumatoid arthritis on sustained remission. Ann Rheum Dis 2007; 66: 358-363.

17. Molenaar ET, Voskuyl AE, Dinant HJ, Bezemer PD, Boers M, Dijkmans BA. Progression of radiologic damage in 
patients with rheumatoid arthritis in clinical remission. Arthritis Rheum 2004; 50: 36-42.

18. Brown AK, Conaghan PG, Karim Z, et al. An explanation for the apparent dissociation between clinical remission and continued structural deterioration in rheumatoid arthritis. Arthritis Rheum 2008; 58: 2958-2967.

19. Mäkinen H, Kautiainen H, Hannonen P, et al. Sustained remission and reduced radiographic progression with combination disease modifying antirheumatic drugs in early rheumatoid arthritis. J Rheumatol 2007; 34: 316-321.

20. Brown AK, Quinn MA, Karim Z, et al. Presence of significant synovitis in rheumatoid arthritis patients with diseasemodifying antirheumatic drug-induced clinical remission: evidence from an imaging study may explain structural progression. Arthritis Rheum 2006; 54: 3761-3773.

21. Conaghan PG, O'Connor P, McGonagle D, et al. Elucidation of the relationship between synovitis and bone damage: a randomized magnetic resonance imaging study of individual joints in patients with early rheumatoid arthritis. Arthritis Rheum 2003; 48: 64-71.

22. Naredo E, Collado P, Cruz A, et al. Longitudinal power Doppler ultrasonographic assessment of joint inflammatory activity in early rheumatoid arthritis: predictive value in disease activity and radiologic progression. Arthritis Rheum 2007; 57: 116-124.

23. Felson DT, Smolen JS, Wells G, et al. American College of Rheumatology/European League against Rheumatism provisional definition of remission in rheumatoid arthritis for clinical trials. Ann Rheum Dis 2011; 70: 404-413.

24. Smolen JS, Han C, van der Heijde DM, et al. Radiographic changes in rheumatoid arthritis patients attaining different disease activity states with methotrexate monotherapy and infliximab plus methotrexate: the impacts of remission and TNF-blockade. Ann Rheum Dis 2009; 68: 823-827.

25. Smolen JS, Han C, Bala M, et al; ATTRACT Study Group. Evidence of radiographic benefit of treatment with infliximab plus methotrexate in rheumatoid arthritis patients who had no clinical improvement: a detailed subanalysis of data from the anti-tumor necrosis factor trial in rheumatoid arthritis with concomitant therapy study. Arthritis Rheum 2005; 52: 1020-1030.

26. Landewe R, van der Heijde D, Klareskog L, van Vollenhoven R, Fatenejad S. Disconnect between inflammation and joint destruction after treatment with etanercept plus methotrexate: results from the trial of etanercept and methotrexate with radiographic and patient outcomes. Arthritis Rheum 2006; 54: 3119-3125.

27. Saleem B, Brown AK, Keen H, et al. Disease remission state in patients treated with the combination of tumor necrosis factor blockade and methotrexate or with diseasemodifying antirheumatic drugs: A clinical and imaging comparative study. Arthritis Rheum 2009; 60: 1915-1922.

28. Cañete JD, Pablos JL. Biologic therapy in rheumatoid arthritis. Curr Top Med Chem 2013; 13: 752-759.

29. Ramírez J, Ruíz-Esquide V, Pomés I, et al. Patients with rheumatoid arthritis in clinical remission and ultrasounddefined active synovitis exhibit higher disease activity and increased serum levels of angiogenic biomarkers. Arthritis Res Ther 2014; 16: R5.

30. Backhaus M, Kamradt T, Sandrock D, et al. Arthritis of the finger joints: a comprehensive approach comparing conventional radiography, scintigraphy, ultrasound, and contrast-enhanced magnetic resonance imaging. Arthritis Rheum 1999; 42: 1232-1245.

31. Backhaus M, Burmester GR, Sandrock D, et al. Prospective two year follow up study comparing novel and conventional imaging procedures in patients with ar- thritic finger joints. Ann Rheum Dis 2002; 61: 895-904.

32. Grassi W, Salaffi F, Filippucci E. Ultrasound in rheumatology. Best Pract Res Clin Rheumatol 2005;19: 467-485.

33. Kane D, Balint PV, Sturrock RD. Ultrasonography is superior to clinical examination in the detection and localization of knee joint effusion in rheumatoid arthritis. J Rheumatol 2003; 30: 966-971.

34. Karim Z, Wakefield RJ, Quinn M, et al. Validation of ultrasonography in the detection of synovitis in the knee: a comparison with arthroscopy and clinical examination. Arthritis Rheum 2004; 50: 387-394.

35. Szkudlarek M, Narvestad E, Klarlund M, Court-Payen M, Thomsen HS, Ostergaard M. Ultrasonography of the metatarsophalangeal joints in rheumatoid arthritis: comparison with magnetic resonance imaging, conventional radiography, and clinical examination. Arthritis Rheum 2004; 50: 2103-2112.

36. Taylor PC, Steur A, Gruber J, et al. Comparison of ultrasonographic assessment of synovitis and joint vascularity with radiographic evaluation in a randomized, placebocontrolled study of infliximab therapy in early rheumatoid arthritis. Arthritis Rheum 2004; 50: 1107-1116.

37. Wakefield RJ, Green MJ, Marzo-Ortega H, et al. Should oligoarthritis be reclassified? Ultrasound reveals a high prevalence of subclinical disease. Ann Rheum Dis 2004; 63: $382-385$.

38. Wakefield RJ, Balint PV, Szkudlarek M, et al. Musculoskeletal ultrasound including definitions for ultrasonographic pathology. J Rheumatol 2005; 32: 2485-2487.

39. Wakefield RJ, D'Agostino MA, Iagnocco A, et al; OMERACT Ultrasound Group. The OMERACT ultrasound group: status of current activities and research directions. J Rheumatol 2007; 34: 848-851

40. Hetland ML, Stengaard-Pedersen K, Junker P, et al. Radiographic progression and remission rates in early rheumatoid arthritis - MRI bone oedema and anti-CCP predicted radiographic progression in the 5-year extension of the doubleblind randomised CIMESTRA trial. Ann Rheum Dis 2010; 69: 1789-1795.

41. Mandl P, Balint PV, Brault Y, et al. Metrologic properties of ultrasound versus clinical evaluation of synovitis in rheumatoid arthritis results of a multicenter, randomized study. Arthritis Rheum 2012; 64: 1272-1282.

42. Newman JS, Laing TJ, McCarthy CJ, Adler RS. Power Doppler sonography of synovitis: assessment of therapeutic response-preliminary observations. Radiology 1996; 198: $582-584$ 
43. Hau M, Kneitz C, Tony HP, Keberle M, Jahns R, Jenett M. High resolution ultrasound detects a decrease in pannus vascularisation of small finger joints in patients with rheumatoid arthritis receiving treatment with soluble tumour necrosis factor alpha receptor (etanercept). Ann Rheum Dis 2002; 61: 55-58.

44. Schmidt WA, Volker L, Zacher J, Schlafke M, Ruhnke M, Gromnica-Ihle E. Colour Doppler ultrasonography to detect pannus in knee joint synovitis. Clin Exp Rheumatol 2000; 18: 439-444.

45. Walther M, Harms H, Krenn V, Radke S, Faehndrich TP, Gohlke F. Correlation of power Doppler sonography with vascularity of the synovial tissue of the knee joint in patients with osteoarthritis and rheumatoid arthritis. Arthritis Rheum 2001; 44: 331-338.

46. Giovagnorio F, Martinoli C, Coari G. Power Doppler sonography in knee arthritis-a pilot study. Rheumatol Int 2001; 20: 101-104.

47. Porta F, Radunovic G, Vlad V, et al. The role of Doppler ultrasound in rheumatic diseases. Rheumatology 2012; 51: 976-982.

48. Picano E, Matucci-Cerinic M. Unnecessary radiation exposure from medical imaging in the rheumatology patient. Rheumatology 2011; 50: 1537-1539.

49. McAlindon T, Kissin E, Nazarian L, et al. American College of Rheumatology report on reasonable use of musculoskeletal ultrasonography in rheumatology clinical practice. Arthritis Care Res (Hoboken) 2012; 64: 1625-1640.

50. Klauser AS, Tagliafico A, Allen GM, et al. Clinical indications for musculoskeletal ultrasound: a Delphi-based consensus paper of the European Society of Musculoskeletal Radiology. EurRadiol 2012; 22: 1140-1148.

51. Filippucci E, Iagnocco A, Salaffi F, Cerioni A, Valesini G, Grassi W. Power Doppler sonography monitoring of synovial perfusion at the wrist joints in patients with rheumatoid arthritis treated with adalimumab. Ann Rheum Dis 2006; 65: 1433-1437.

52. Naredo E, Rodriguez M, Campos C, et al. Validity, reproducibility, and responsiveness of a twelve-joint simplified power dopplerultrasonographic assessment of joint inflammation in rheumatoid arthritis. Arthritis Rheum 2008; 4: 515-522.

53. Iagnocco A, Finucci A, Ceccarelli F, Perricone C, Iorgoveanu V, Valesini G. Power Doppler ultrasound monitoring of response to antitumornecrosis factor alpha treatment in patients with rheumatoid arthritis. 2015 June 11. doi:10.1093/ rheumatology/kev211

54. Thakkar V, Joshua F, Bird P, Katrib A, Bertouch J. The role of ultrasound in patient understanding and compliance in early rheumatoid arthritis. Proceedings of the ARP87, ARA-THPA 51st Annual Scientific Meeting; 2010; Melbourne, Australia.

55. Backhaus M, Burmester GR, Gerber T, et al. Guidelines for musculoskeletal ultrasound in rheumatology. Ann Rheum Dis 2001; 60: 641-649.

56. Torp- Pedersen S, Christensen R, Szkudlarek M, et al. Power and color Doppler ultrasound settings for inflammatory flow: impact on scoring of disease activity in patients with rheumatoid arthritis. Arthritis Rheumatol 2015; 67: 386395.

57. Ohrndorf S, Backhaus M. Advances in sonographic scoring of rheumatoid arthritis. Ann Rheum Dis 2013; 72 Suppl 2: ii69-ii75.

58. Szkudlarek M, Court-Payen M, Jacobsen S, Klarlund M, Thomsen HS, Ostergaard M. Interobserver agreement in ultrasonography of the finger and toe joints in rheumatoid arthritis. Arthritis Rheum 2003; 48: 955-962.

59. Boers M, Brooks P, Strand CV, Tugwell P. OMERACT filter for outcome measures in rheumatology. J Rheumatol 2005; 25: 198-199.

60. Lassere MN. Imaging: the need for standardisation. Best Pract Res Clin Rheumatol 2008; 22: 1001-1018.

61. Szkudlarek M, Wakefield RJ, Backhaus M, Terslev L. The discriminatory capacity of ultrasound in rheumatoid arthritis: active vs inactive, early vs advanced, and more. Rheumatology 2012; 51 Supp1 7: vii6-vii9.

62. Szkudlarek M, Court-Payen M, Strandberg C, Karlund M, Klausen T, Ostergaard M. Power Doppler ultrasonography for assessment of synovitis in the metacarpophalangeal joints of patients with rheumatoid arthritis. a comparison with dynamic magnetic resonance imaging. Arthritis Rheum 2001; 44: 2018-2023.

63. Andersen M, Ellegaard K, Hebsgaard JB, et al. Ultrasound colour Doppler is associated with synovial pathology in biopsies from hand joints in rheumatoid arthritis patients: a cross-sectional study. Ann Rheum Dis 2014; 73: 678-683.

64. Terslev L, Torp- Pedersen S, Savnik A, et al. Doppler ultrasound and magnetic resonance imaging of synovial inflammation of the hand in rheumatoid arthritis: a comparative study. Arthritis Rheum 2003; 48: 2434-2441.

65. Fukae J, Kon Y, Henmi M, et al. Change of synovial vascularity in a single finger joint assessed by power doppler sonography correlated with radiographic change in rheumatoid arthritis: comparative study of a novel quantitative score with a semiquantitative score. Arthritis Care Res (Hoboken) 2010; 62: 657-663.

66. Motomura H, Matsushita I, Seki E, Kimura T. Correlation of power doppler' ultrasonographic findings with sitematched histopathology of the synovial tissue. Ann Rheum Dis 2013; 72(suppl 3): A546-A547.

67. Ribbens C, André B, Marcelis S, et al. Rheumatoid hand joint synovitis: gray-scale and power Doppler US quantifications following anti-tumor necrosis factor- $\alpha$ treatment: pilot study. Radiology 2003; 229: 562-569.

68. Hammer HB, Kvien TK. Ultrasonography shows significant improvement in wrist and ankle tenosynovitis in rheumatoid arthritis patients treated with adalimumab. Scand J Rheumatol 2011; 40: 178-182.

69. Døhn UM, Ejbjerg B, Boonen A, et al. No overall progression and occasional repair of erosions despite persistent inflammation in adalimumab-treated rheumatoid arthritis patients: results from a longitudinal comparative MRI, ultrasonography, CT and radiography study. Ann Rheum Dis 2011; 70: 252-258. 
70. Hartung W, Kellner H, Strunk J, et al. Development and evaluation of a novel ultrasound score for large joints in rheumatoid arthritis: one year of experience in daily clinical practice. Arthritis Care Res 2012; 64: 675-682.

71. Damjanov N, Radunovic G, Prodanovic S, et al. Construct validity and reliability of ultrasound disease activity score in assessing joint inflammation in RA: comparison with DAS-28. Rheumatology 2012; 51: 120-128.

72. Wakefield RJ, O'Connor PJ, Conaghan PG, et al. Finger tendon disease in untreated early rheumatoid arthritis: a comparison of ultrasound and magnetic resonance imaging. Arthritis Rheum 2007; 57: 1158-1164.

73. Scire CA, Montecucco C, Codullo V, Epis O, Todoerti M, Caporali R. Ultrasonographic evaluation of joint involvement in early rheumatoid arthritis in clinical remission: power Doppler signal predicts short-term relapse. Rheumatology 2009; 48: 1092-1097

74. Peluso G, Michelutti A, Bosello S, Gremese E, Tolusso B, Ferraccioli G. Clinical and ultrasonographic remission determines different chances of relapse in early and long standing rheumatoid arthritis. Ann Rheum Dis 2011; 70: 172-175.

75. Scheel AK, Hermann KG, Ohrndorf S, et al. Prospective 7 year follow up imaging study comparing radiography, ultrasonography, and magnetic resonance imaging in rheumatoid arthritis finger joints. Ann Rheum Dis 2006; 65: 595-600.

76. Saleem B, Keen H, Goeb V, et al. Patients with RA in remission on TNF blockers: when and in whom can TNF blocker therapy be stopped? Ann Rheum Dis 2010; 69: 1636-1642.

77. Saleem B, Brown AK, Keen H, et al. Disease remission state in patients treated with the combination of tumor necrosis factor blockade and methotrexate or with diseasemodifying antirheumatic drugs: A clinical and imaging comparative study. Arthritis Rheum 2009; 60: 1915-1922.

78. Saleem B, Brown AK, Quinn M, et al. Prediction of flare and long-term outcome in DMARD treated ra patients in remission: the value of imaging and new remission criteria. Ann Rheum Dis 2011; 70(Suppl 3): 88.

79. Balsa A, de Miguel E, Castillo C, Peiteado D, Martín-Mola E. Superiority of SDAI over DAS-28 in assessment of remission in rheumatoid arthritis patients using power Doppler ultrasonography as a gold standard. Rheumatology (Oxford) 2010; 49: 683-690.

80. Foltz V, Gandjbakhch F, Etchepare F, et al. Power Doppler ultrasound, but not low-field magnetic resonance imaging, predicts relapse and radiographic disease progression in rheumatoid arthritis patients with low levels of disease activity. Arthritis Rheum 2012; 64: 67-76.

81. Naredo E, Acebes C, Brito E, et al; Ultrasound School of the Spanish Society of Rheumatology. Three-dimensional volumetric ultrasound: a valid method for blinded assessment of response to therapy in rheumatoid arthritis. J Rheumatol 2013; 40: 253-260.

82. Geng Y, Han J, Deng X, Zhang Z. Presence of power Doppler synovitis in rheumatoid arthritis patients with synthetic and/or biological disease-modifying anti-rheumatic drug- induced clinical remission: experience from a Chinese cohort. Clin Rheumatol 2014; 33: 1061-1066.

83. Zufferey P, Möller B, Brulhart L, et al. Persistence of ultrasound synovitis in patients with rheumatoid arthritis fulfilling the DAS28 and/or the new ACR/EULAR RA remission definitions: results of an observational cohort study. Joint Bone Spine 2014; 81: 426-432.

84. Bøyesen P, Haavardsholm EA, Østergaard M, van der Heijde D, Sesseng S, K Kvien T. MRI in early rheumatoid arthritis: synovitis and bone marrow oedema are independent predictors of subsequent radiographic progression. Ann Rheum Dis 2011; 70: 428-433.

85. Freeston JE, Wakefield RJ, Conaghan PG, Hensor EM, Stewart SP, Emery P. A diagnostic algorithm for persistence of very early inflammatory arthritis: the utility of power Doppler ultrasound when added to conventional assessment tools. Ann Rheum Dis 2010; 69: 417-419.

86. Funck -Bretano T, Grandjbakhch F, Etchepare F, et al. Prediction of radiographic damage in early arthritis by sonographic erosions and power Doppler signal: a longitudinal observational study. Arthritis Care Res 2013; 65: 896-902.

87. Dougados M, Kissel K, Sheeran T, et al. Adding tocilizumab or switching to tocilizumab monotherapy in methotrexate inadequate responders: 24-week symptomatic and structural results of a 2-year randomised controlled strategy trial in rheumatoid arthritis (ACT-RAY). Ann Rheum Dis 2013; 72: 43-50.

88. Dougados M, Devauchelle-Pensec V, Ferlet JF, et al. The ability of synovitis to predict structural damage in rheumatoid arthritis: a comparative study between clinical examination and ultrasound. Ann Rheum Dis 2013; 72: 665-671.

89. Macchioni P, Magnani M, Mulè R, et al. Ultrasonographic predictors for the development of joint damage in rheumatoid arthritis patients: a single joint prospective study. Clin Exp Rheumatol 2013; 31: 8-17.

90. Hama M, Uehara T, Takase K, et al. Power Doppler ultrasonography is useful for assessing disease activity and predicting joint destruction in rheumatoid arthritis patients receiving tocilizumab-preliminary data. Rheumatol Int 2012; 32: 1327-1333.

91. Kawashiri SY, Suzuki T, Nakashima Y, et al. Ultrasonographic examination of rheumatoid arthritis patients who are free of physical synovitis: power Doppler subclinical synovitis is associated with bone erosion. Rheumatology (Oxford) 2014; 53: 562-569.

92. Yoshimi R, Hama M, Takase K, et al. Ultrasonography is a potent tool for the prediction of progressive joint destruction during clinical remission of rheumatoid arthritis. Mod Rheumatol 2013; 23: 456-465.

93. Kawashiri SY, Kawakami A, Iwamoto N, et al. The power Doppler ultrasonography score from 24 synovial sites or 6 simplified synovial sites, including the metacarpophalangeal joints, reflects the clinical disease activity and level of serum biomarkers in patients with rheumatoid arthritis. Rheumatology 2011; 50: 962-965.

94. Korpela M, Laasonen L, Hannonen P, et al. Retardation of joint damage in patients with early rheumatoid arthritis by 
initial aggressive treatment with disease-modifying antirheumatic drugs: five-year experience from the FIN- RACo study. Arthritis Rheum 2004; 50: 2072-2081.

95. Möttönen T, Hannonen P, Korpela M, et al. Delay to institution of therapy and induction of remission using singledrug or combination-disease-modifying antirheumatic drug therapy in early rheumatoid arthritis. Arthritis Rheum 2002; 46: 894-898.

96. Østergaard M, Hansen M, Stoltenberg M, et al. New radiographic bone erosions in the wrists of patients with rheumatoid arthritis are detectable with magnetic resonance imaging a median of two years earlier. Arthritis Rheum 2003; 48: 2128-2131.

97. Nell VP, Machold KP, Eberl G, Stamm TA, Uffmann M, Smolen JS. Benefit of very early referral and very early therapy with disease-modifying anti-rheumatic drugs in patients with early rheumatoid arthritis. Rheumatology (Oxford) 2004; 43: 906-914.

98. Emery P, Kvien TK, Combe B, et al. Very early ( $<4$ months) treatment with combination etanercept (etn) and methotrexate $(\mathrm{mtx})$ produces significantly better remission rates: results from the COMET study. Ann Rheum Dis 2010; 69 (Suppl 3): 57.

99. Aletaha D, Funovits J, Breedveld FC, Sharp J, Segurado $\mathrm{O}$, Smolen JS. Rheumatoid arthritis joint progression in sustained remission is determined by disease activity levels preceding the period of radiographic assessment. Arthritis Rheum 2009; 60: 1242-1249.

100. Radner H, Alasti F, Smolen JS, Aletaha D. Time in remission is important for improvement of physical function in patients with rheumatoid arthritis (RA). [abstract]. Arthritis Rheum 2012; 64 Suppl 10: 2608.

101. Naredo E, Valor L, De la Torre I, et al. Predictive value of Doppler ultrasound-detected synovitis in relation to failed tapering of biologic therapy in patients with rheumatoid arthritis. Rheumatology (Oxford) 2015; 54: 1408-1414.

102. Filippucci E, Salaffi F, Carotti M, Grassi W. Doppler ultrasound imaging techniques for assessment of synovial inflammation. Reports in Medical Imaging 2013;6: 83-91.

103. Mandl P, Naredo E, Wakefield RJ, Conaghan PG, D'Agostino MA; OMERACT Ultrasound Task Force. A systematic literature review analysis of ultrasound joint count and scoring systems to assess synovitis in rheumatoid arthritis according to the OMERACT filter. J Rheumatol 2011; 38: 2055-2062.

104. Neogi T, Felson DT. Composite versus individual measures of disease activity in rheumatoid arthritis. J Rheumatol 2008; 35: 185-187.

105. Mandl P, Kurucz R, Niedermayer D, Balint PV, Smolen JS. Contributions of ultrasound beyond clinical data in assessing inflammatory disease activity in rheumatoid arthritis: current insights and future prospects. Rheumatology 2014; 53: 2136-2142.

106. Backhaus M, Ohrndorf S, Kellner H, et al. Evaluation of a novel 7-joint ultrasound score in daily rheumatologic practice: a pilot project. Arthritis Rheum 2009; 61: 1194-1201.
107. Perricone C, Ceccarelli F, Modesti M, et al. The 6-joint ultrasonographic assessment: a valid, sensitive-to-change and feasible method for evaluating joint inflammation in RA. Rheumatology (Oxford) 2012; 51: 866-873.

108. Hammer HB, Kvien TK. Comparisons of 7- to 78-joint ultrasonography scores: all different joint combinations show equal response to adalimumab treatment in patients with rheum. Arthritis Res Ther 2011; 13: R78.

109. Grassi W, Gaywood I, Pande I, Filippucci E. From DAS 28 to SAS 1. Clin Exp Rheumatol 2012; 30: 649-651.

110. Ten Cate DF, Luime JJ, Swen N, et al. Role of ultrasonography in diagnosing early rheumatoid arthritis and remission of rheumatoid arthritis - a systematic review of the literature. Arthritis Res Ther 2013; 15: R4.

111. Dougados M, Jousse-JoulinS, Mistretta F, et al. Evaluation of several ultrasonography scoring systems for synovitis and comparison to clinical examination: results from a prospective multicentre study of rheumatoid arthritis. Ann Rheum Dis 2010; 69: 828-833.

112. Hammer HB, Kvien T. Ultrasound tenosynovitis score is responsive to biologic treatment in patients with rheumatoid arthritis. Arthritis Rheum 2014; 66 (Suppl 10): S401S402.

113. Heegaard C, Dreyer L, Egsmose C, Madsen OR. Test-retest reliability of the disease activity score 28 CRP (DAS28$\mathrm{CRP})$, the simplified disease activity index (SDAI) and the clinical disease activity index (CDAI) in rheumatoid arthritis when based on patient self-assessment of tender and swollen joints. Clin Rheumatol 2013; 32: 1493-1500.

114. Witt M, Mueller F, Nigg A, et al. Relevance of grade 1 gray- scale ultrasound findings in wrists and small joints to the assessment of subclinical synovitis in rheumatoid arthritis. Arthritis Rheum 2013; 65: 1694-1701.

115. Gartner M, Mandl P, Radner H, et al. Sonographic joint assessment in rheumatoid arthritis: associations with clinical joint assessment during a state of remission. Arthritis Rheum 2013; 65: 2005-2014.

116. Grassi W, Filippucci E. Is power Doppler sonography the new frontier in therapy monitoring? Clin Exp Rheumatol 2003; 21: 424-428.

117. Backhaus TM, Ohrndorf S, Kellner H, et al. The US7 score is sensitive to change in a large cohort of patients with rheumatoid arthritis over 12 months of therapy. Ann Rheum Dis 2013; 72: 1163-1169.

118. Kamishima T, Sagawa A, Tanimura K, et al. Semi-quantitative analysis of rheumatoid finger joint synovitis using power Doppler ultrasonography: when to perform follow-up study after treatment consisting mainly of antitumor necrosis factor alpha agent. Skeletal Radiol 2010; 39: 457-465.

119. Dixey J, Solymossy C, Young A; Early RA Study. Is it possible to predict radiological damage in early rheumatoid arthri- tis (RA)? A report on the occurrence, progression, and prognostic factors of radiological erosions over the first 3 years in 866 patients from the Early RA Study (ERAS). J Rheumatol Suppl 2004; 69: 48-54.

120. Wechalekar MD, Lester S, Proudman S, et al. Active foot synovitis in patients with rheumatoid arthritis applying 
clinical criteria for disease activity and remission may result in underestimation of foot joint involvement. Arthritis Rheum 2012; 64: 1316-1322.

121. O'Dell JR, Mikuls TR. To improve outcomes we must define and measure them: toward defining remission in rheumatoid arthritis. Arthritis Rheum 2011; 63: 587-589.

122. Fodor D, Felea I, Popescu D, et al. Ultrasonography of metacarpophalangeal joints in healthy subjects using an 18 MHz transducer. Med Ultrason 2015; 17: 185-191.
123. Ceponis A, OnishiM, Bluestein HG, Kalunian K, Townsend J, Kavanaugh A. Utility of the ultrasound examination of the hand and wrist joints in the management of established rheumatoid arthritis. Arthritis Care Res 2014; 66: 236-244.

124. Colebatch AN, Edwards CJ, Ostergaard M, et al. EULAR recommendations for the use of imaging of the joints in the clinical management of rheumatoid arthritis. Ann Rheum Dis 2013 ; 72: 804-814. 